\title{
Investigating blue phosphorescent iridium cyclometalated dopant with phenyl-imidazole ligands
}

Kevin P. Klubek ${ }^{\mathrm{a}}$, Shou-Cheng Dong ${ }^{\mathrm{b}}$, Liang-Sheng Liao ${ }^{\mathrm{b},}$, Ching W. Tang ${ }^{\mathrm{a},}$, Lewis J. Rothberg ${ }^{\mathrm{a}, \mathrm{c}}$

${ }^{a}$ Department of Chemical Engineering, University of Rochester, Rochester, New York, 14627, USA.

bJiangsu Key Laboratory for Carbon-Based Functional Materials \& Devices, Institute of Functional Nano \& Soft Materials (FUNSOM), Soochow University, Suzhou, Jiangsu 215123, China.

${ }^{\mathrm{c}}$ Department of Chemistry, University of Rochester, Rochester, New York, 14627, USA.

\begin{abstract}
:
A blue phosphorescent emitter based on tris[1-(2,6-diisopropylphenyl)-2-phenyl-1Himidazole]iridium(III), Ir(iprpmi) $)_{3}$, as the dopant and 3,3'-bis(N-carbazolyl)biphenyl, mCBP, as the host have been evaluated in OLED devices. By optimizing the dopant concentration and the materials for the electron and hole-transport layers, external quantum efficiencies greater than $20 \%$ have been achieved. Improved device lifetimes over those using the classic light-blue dopant FIrpic have also been achieved. These improvements can be attributed to the control of the electron-hole recombination and emission regions within the emitter layer as well as the choice of material for the transport layers.
\end{abstract}

\section{Keywords:}

Organic light-emiting diodes; blue oled; phosphorescent emitter; Ir complex; lifetime study

\section{Introduction}

A key advance in OLED technology can be attributed to the development of highly efficient phosphorescent OLEDs, known as PHOLEDs. Based on phosphorescent molecules as the emitter, including most notably the class of iridium(III) cyclometalated complexes [14], PHOLEDs with nearly $100 \%$ quantum efficiencies $[5,6]$ across the visible spectrum have been demonstrated. In addition, excellent lifetime $(>100,000 \mathrm{~h})$ has been achieved for red and

\footnotetext{
*E-mail: chtang@,che.rochester.edu, 1sliao@suda.edu.cn
} 
green PHOLEDs. However, the lifetime for blue PHOLEDs remains relatively short (typically less than 10,000 h) [7] and inadequate for most applications, such as display and lighting.

Considerable research efforts have focused on developing efficient and stable blue phosphorescent PHOLEDs [8]. However, there are few reports on the structure-property relationships for phosphorescent molecules as they pertain to device lifetime. Among the most studied phosphorescent molecules is bis(4,6-difluorophenyl-pyridinato- $N, \mathrm{C} 2)$ picolinate iridium(III), FIrpic. Used as a dopant in blue PHOLEDs, it is capable of achieving an external quantum efficiency (EQE) greater than 20\% [9-14]. However, FIrpic doped PHOLEDs have been shown to be very unstable. Reported lifetimes are in the range of 0.1-110 hours depending on the device architecture and test conditions [15-18]. In our tests, we have observed that the lifetime of FIrpic-based devices can vary from 5 minutes to 12 hours depending on the choice of host and transport materials. The instability of FIrpic doped PHOLEDs has been largely attributed to the intrinsic instability of Flrpic molecules upon excitation. Both the ancillary picolinate ligand and the fluorine substituted phenyl-pyridyl ligands are susceptible to photo-induced dissociation [17, 19, 20]. It has also been reported that FIrpic is unstable to hole transport [21]. To avoid the detrimental structural features present in FIrpic, we have examined Ir complexes with phenyl-imidizole ligands, which reportedly can provide PHOLEDs with lifetimes as long as 10,000 hours [22-29].

In this work we have performed a detailed study of one such dopant, tris[1-(2,6diisopropylphenyl)-2-phenyl-1H-imidazole]iridium(III), Ir(iprpmi) $)_{3}$. We will show that its performance as a blue phosphorescent dopant is not only related to its intrinsic photophysical properties, but also highly dependent on the compositions of the host matrix and the adjacent transport layers.

\section{Material and methods}

The following materials used in this study were purchased from Luminescence Technology Corporation and used as received, 3,3'-bis(N-carbazolyl)biphenyl (mCBP), tris[1- 
(2,6-diisopropylphenyl)-2-phenyl-1H-imidazole]iridium(III) (Ir(iprpmi) $\left.)_{3}\right)$, and 1,3,5-tri(mpyrid-3-yl-phenyl)benzene (TmPyPB). The following materials were obtained from Eastman Kodak Company, 4,4'-bis[N-(1-naphthyl)-N-phenyl-amino]-biphenyl (NPB), 1, 1-bis( di-4tolylaminophenyl)cyclohexane (TAPC) and bis-(2-methyl-8-quinolinolate)-4(phenylphenolate)aluminum (III) (BAlq). Figure 1 shows the molecular structures and the energy level diagram (HOMO/LUMO) for all materials used in this work. Highest occupied molecular orbital (HOMO), lowest unoccupied molecular orbital (LUMO) and triplet energy values for the following materials were based on reports in the literature, NPB [30, 31], TAPC [32, 33], mCBP [34], BAlq [35], and TmPyPB [36].
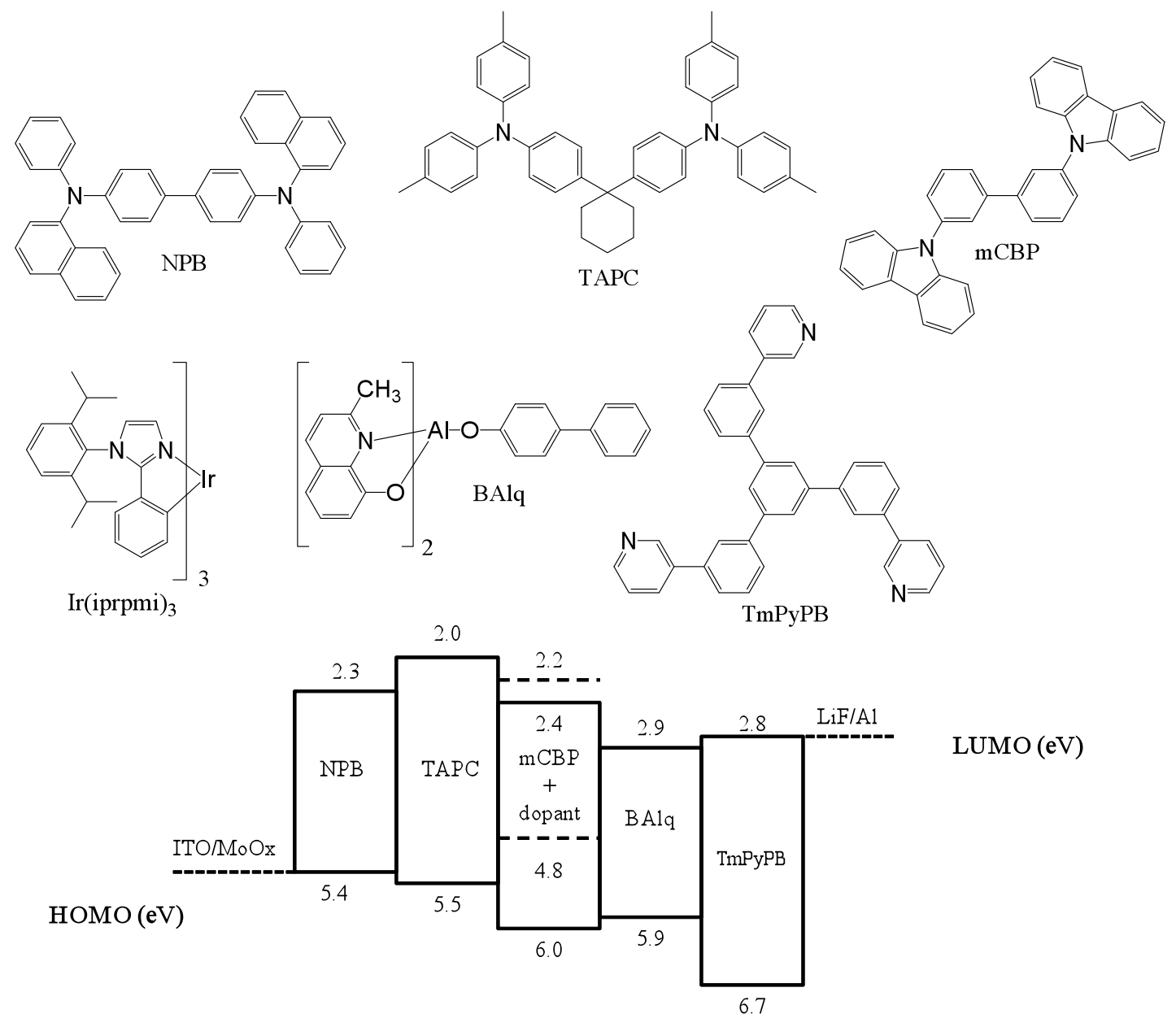

$\operatorname{LUMO}(\mathrm{eV})$

Figure 1: Molecular structures and representative energy level diagram of the materials (values in $\mathrm{eV}$ ). 
UV-Vis absorption spectra were obtained using a Perkin Elmer Lambda 750 spectrophotometer. PL spectra and phosphorescent spectra were recorded on a Hitachi F-4600 fluorescence spectrophotometer. Cyclic voltammetry (CV) was carried out on a CHI600 voltammetric analyzer at room temperature with a conventional three-electrode configuration consisting of a platinum disk working electrode, a platinum wire auxiliary electrode, and an $\mathrm{Ag}$ wire pseudo-reference electrode with ferrocenium-ferrocene $\left(\mathrm{Fc}^{+} / \mathrm{Fc}\right)$ as the internal standard. Deaerated dichloromethane was used as solvent. UPS analyses were carried out with an unfiltered HeI (21.2 eV) gas discharge lamp and a hemispherical analyzer. DFT calculations were performed at the B3LYP level. The 6-31g(d) basis set was employed for H, C, $\mathrm{N}$ atoms and a "double- $\zeta$ " quality basis set, LANL2DZ, was employed for the $\operatorname{Ir}(\mathrm{III})$ metal atom. All calculations were carried out using Gaussian 03 [37]. Transient PL spectra were acquired at room temperature using an Edinburgh ELS920 spectrometer for samples dissolved in degassed dichloromethane. The spectrometer was equiped with a time-correlated singlephoton counting option and the lifetime data was analyzed with the companion F900 software. The quantum efficiency was obtained by using $f a c-\operatorname{Ir}(\mathrm{ppy})_{3}$ as a standard [38]. Degassed solutions were prepared by purging with argon for 30 minutes.

OLED devices were fabricated on patterned indium-tin-oxide (ITO, $110 \mathrm{~nm}$ and 15 $\mathrm{ohm} / \mathrm{sq}$ ) coated glass substrates. The substrates were batchwise cleaned by, sequentially, soaking and mechanically scrubbing in detergent solution, washing in deionized water, acetone and isopropanol using an ultrasonic bath, drying with nitrogen and then further treating with $\mathrm{O}_{2}$ plasma. All films were prepared by thermal deposition $\left(<10^{-6}\right.$ Torr $)$ without breaking vacuum until the OLED device was completed with the top aluminum electrode. After fabrication, the OLED devics were transferred to a vacuum assembly for testing, which incurred a brief exposure to the ambient atmosphere. The EL properties of the OLEDs were evaluated using a Photoresearch PR650 SpectraScan Colorimeter and a Keithley 2400 source 
meter at room temperature. The devices were viewed perpendicular to the device plane, and the angular distribution of the EL was assumed to be Lambertian.

\section{Results and discussion:}

\subsection{Photophysical and electrochemical measurements}

Figure 2 shows the UV-Vis absorption and photoluminescence (PL) spectra of $\operatorname{Ir}(\text { iprpmi })_{3}$. The absorption bands below $330 \mathrm{~nm}$ are due to the spin-allowed ligand-centered

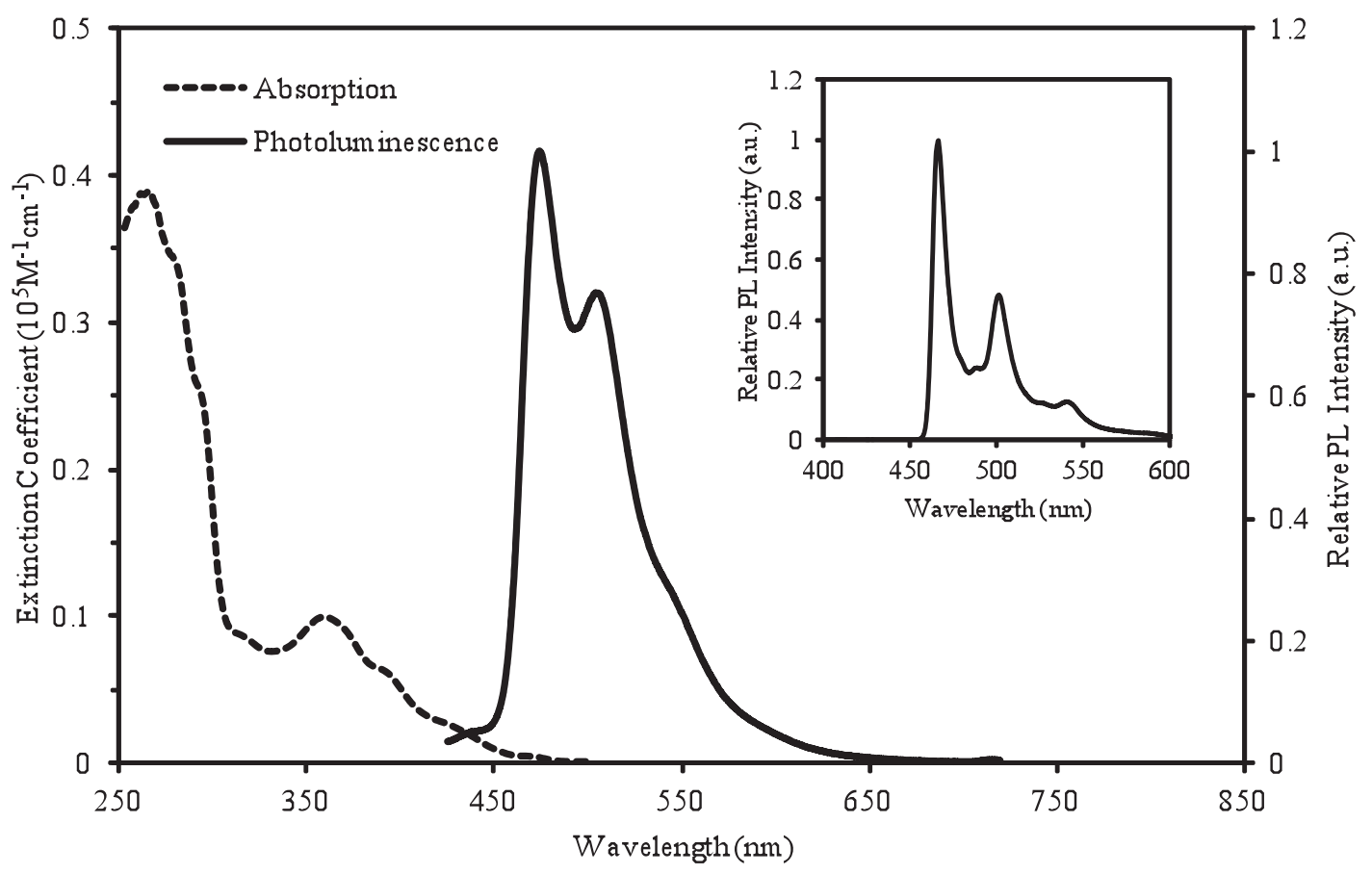

Figure 2: UV-Vis absorption and PL spectra of $\operatorname{Ir}(\text { iprpmi) })_{3}$ in $\mathrm{CH}_{2} \mathrm{Cl}_{2}$. Inset: PL spectrum of $\operatorname{Ir}(\text { iprpmi })_{3}$ in 2 -MeTHF at $77 \mathrm{~K}$.

(LC) ${ }^{1}\left(\pi-\pi^{*}\right)$ transitions of the phenyl-imidizole moiety $[25,39-41]$. The band at $359 \mathrm{~nm}$ is attributed to a spin-allowed metal-to-ligand charge transfer (MLCT) transition [41] while bands longer than $359 \mathrm{~nm}$ are due to mixtures of spin-forbidden LC and MLCT transitions. The PL spectrum has maximum peak intensity at $474 \mathrm{~nm}$ which is similar to what has been reported for FIrpic $(470-472 \mathrm{~nm})[25,42-44]$. There is a secondary peak at $504 \mathrm{~nm}$ and a shoulder at $\sim 550 \mathrm{~nm}$. The solution quantum efficiency for $\operatorname{Ir}(\mathrm{iprpmi})_{3}$ in $\mathrm{CH}_{2} \mathrm{Cl}_{2}$ is 0.57 . The 
triplet energy $\left(E_{T}\right)$ is $2.66 \mathrm{eV}$ as determined by the peak intensity of the shortest wavelength peak in the PL spectrum at $77 \mathrm{~K}$ (inset of Figure 2). The transient PL taken in degassed $\mathrm{CH}_{2} \mathrm{Cl}_{2}$ indicates a lifetime of $1.19 \mu$ s. The highest occupied molecular orbital (HOMO) is 4.8 $\mathrm{eV}$ based on ultraviolet photoelectron spectroscopy (UPS) while the lowest unoccupied molecular orbital (LUMO) is $2.2 \mathrm{eV}$ considering a HOMO-LUMO gap of $2.6 \mathrm{eV}$ as determined by the $0-0$ absorption band $(469 \mathrm{~nm})$. Cyclic voltammetry $(\mathrm{CV})$ indicates that $\operatorname{Ir}(\text { iprpmi })_{3}$ undergoes a reversible one-electron oxidation process with an onset of $-0.15 \mathrm{~V}$. The HOMO based on $\mathrm{CV}$ is $4.7 \mathrm{eV}$ as calculated according to EHOMO $=\mathrm{EFC}+$ Eonsetox wherein $\mathrm{E}_{\mathrm{FC}}$ is the HOMO level of ferrocene $(4.8 \mathrm{eV})$.

Figure 3 depicts the HOMO and LUMO obtained from density functional theory (DFT) calculations. The HOMO is localized in the Ir d-orbital and the $\pi$-orbital of the phenyl moiety on the ligand whereas the LUMO is distributed on the phenyl-imidizole ligand. These electron densities are similar to what has been reported for other phenylimidazolinato Ir (III) complexes [41]. The calculated HOMO level is $4.3 \mathrm{eV}$.

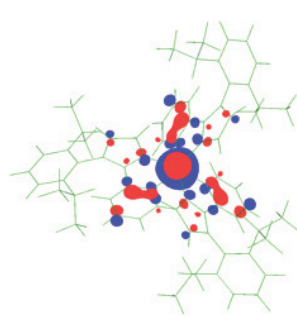

(a)

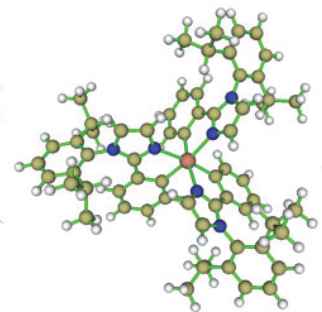

(b)

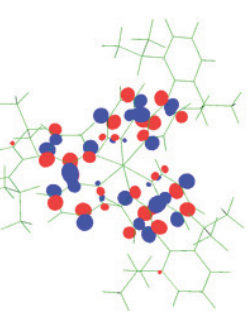

(c)

Figure 3: Simulated frontier molecular orbitals of Ir(iprpmi) $)_{3}$. (a) HOMO electron density, (b) ball and stick model, (c) LUMO electron density.

\subsection{Low EQE OLEDs:}

$\operatorname{Ir}(\text { iprpmi })_{3}$ as a blue phosphorescent dopant in PHOLEDs was first reported in the patent literature by Lin et al. [26]. They showed that $\operatorname{Ir}(\text { iprpmi })_{3}$ and similar dopants with an imidazole as the ligand generally provide a longer lifetime than other blue phosphorescent 
dopants, such as Flrpic. Following Lin's work, we examined in more detail not only the effect of the dopant and host composition of the emitter layer, but also the composition of the adjacent transport layers on the device performance. We fabricated two devices, A1 and A2, with a layer structure as follows: ITO/1.2 nm $\mathrm{MoO}_{\mathrm{x}} / 40 \mathrm{~nm} \mathrm{NPB} / 30 \mathrm{~nm} \mathrm{mCBP}+\mathrm{x} \%$ $\operatorname{Ir}(\text { iprpmi })_{3} / 40 \mathrm{~nm} \mathrm{BAlq} / 1 \mathrm{~nm} \mathrm{LiF} / 100 \mathrm{~nm} \mathrm{Al}$. In this structure, which is similar to that used by Lin, NPB and BAlq are the hole-transport and electron-transport layers, respectively, and mCBP is the host matrix for the $\operatorname{Ir}(\text { iprpmi })_{3}$ in the emitter layer. The concentration of $\operatorname{Ir}(\text { iprpmi })_{3}$ in $\mathrm{mCBP}$ is $6 \%$ for $\mathrm{A} 1$ and $12 \%$ for $\mathrm{A} 2$. Figure 4 compares the electroluminescence characteristics of A1 and A2. The EL spectra as shown in Figure 4(a) are characteristic of $\operatorname{Ir}(\text { iprpmi })_{3}$ emission and relatively independent of concentration. The
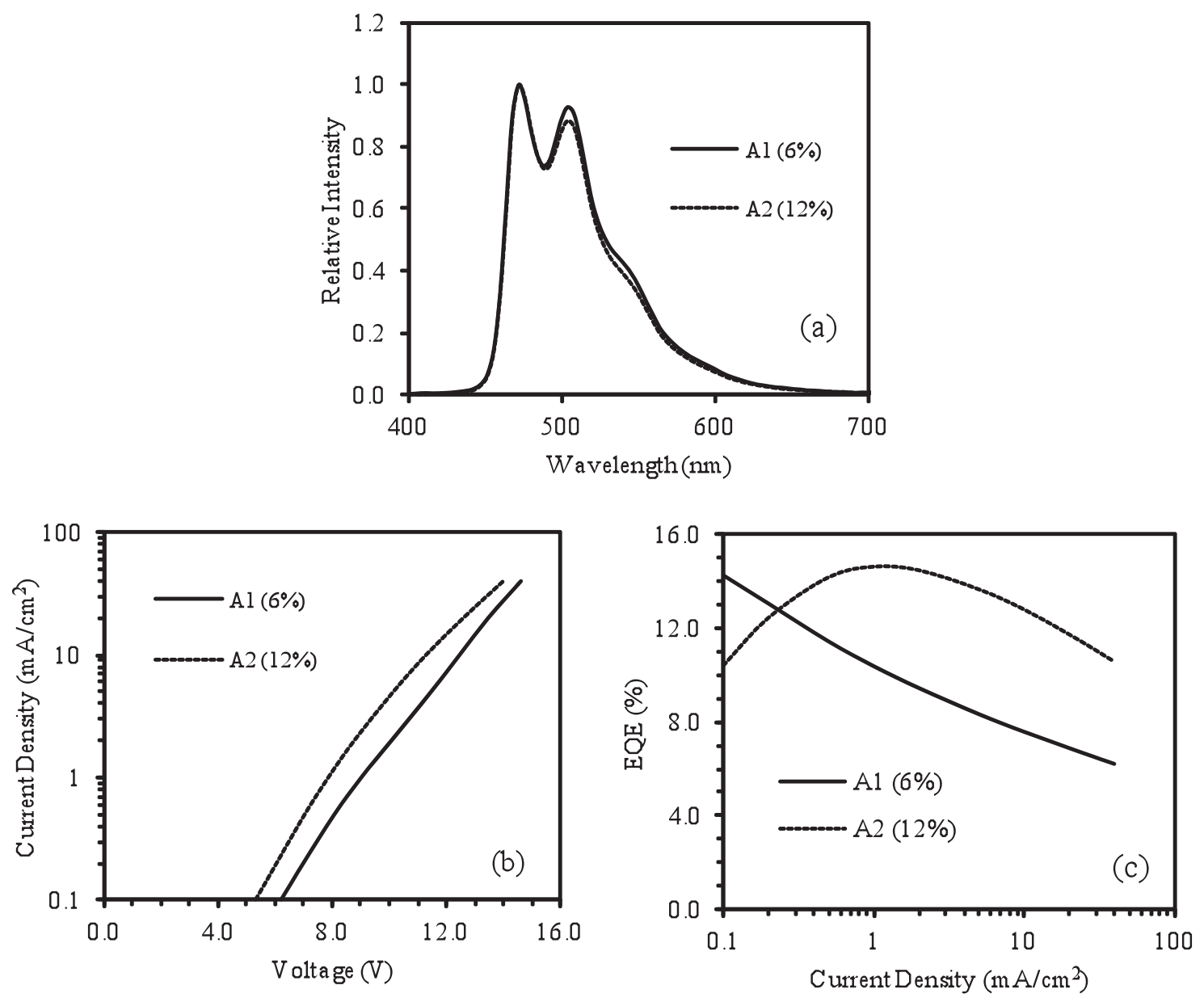

Figure 4: OLED performance data for Ir(iprpmi) ${ }_{3}$ concentration series with NPB HTL and BAlq ETL. ITO/1.2 $\mathrm{nm} \mathrm{MoO}_{\mathrm{x}} / 40$ nm TAPC/30 nm mCBP+ x\% Ir(iprpmi) $)_{3} / 40 \mathrm{~nm} \mathrm{BAlq/1} \mathrm{nm} \mathrm{LiF/100} \mathrm{nm} \mathrm{Al.} \mathrm{A1} \mathrm{[6 \% ],} \mathrm{A2} \mathrm{[12 \% ].} \mathrm{(a)} \mathrm{EL} \mathrm{spectra} \mathrm{at} 5$ $\mathrm{mA} / \mathrm{cm}^{2}$, (b) current density vs. voltage, (c) EQE vs. current density. 
current-voltage curves of Figure 4(b) indicates a shift to lower drive voltage with increasing $\operatorname{Ir}(\text { iprpmi })_{3}$ concentration in the emitter layer, by about $1.3 \mathrm{~V}$ at $5 \mathrm{~mA} / \mathrm{cm}^{2}$. As shown in Figure 4(c), the EQE dependence on drive current density is different for A1 and A2. Although both A1 and A2 can reach an EQE maximum of about 14\%, they achieve their maxima at different current densities. At $5 \mathrm{~mA} / \mathrm{cm}^{2}$, the EQE is $8.4 \%$ for A1 with $6 \%$ $\operatorname{Ir}(\text { iprpmi })_{3}$ compared to $13.7 \%$ for A2 with $12 \% \operatorname{Ir}(\text { iprpmi })_{3}$. Similar to what has been reported by Lin et al, the maximum EQE values ( 14\%) are substantially lower than what can be expected from similar Ir-based dopants. The triplet energy levels of NPB and BAlq are $2.41 \mathrm{eV}$ and $2.18 \mathrm{eV}$, respectively, which are lower than that of $\operatorname{Ir}(\text { iprpmi })_{3}(2.66 \mathrm{eV})$. Thus both NPB and BAlq can cause quenching of the $\operatorname{Ir}(\text { iprpmi })_{3}$ triplet excitons generated by electron-hole recombination in the emitter layer and the extent of quenching will depend on the proximity of the recombination zone relative to the interfaces with NPB and BAlq. The effect of shifting the recombination zone on device performance is explored further in the following sections.

\subsection{High EQE OLEDs:}

In the layer structure described above, the $\operatorname{Ir}(\text { iprpmi })_{3}$ doped emitter layer was sandwiched between the hole-transport layer NPB and the electron-transport layer BAlq. To examine exciton quenching by the hole-transport layer, we fabricated devices B1-B6 with a layer structure similar to devices A1 and A2, except that NPB is substituted by TAPC for the hole-transport layer. TAPC was chosen to eliminate the possibility of exciton quenching since the triplet energy of TAPC $(2.9 \mathrm{eV})$ is significantly higher than that of $\operatorname{Ir}(\text { iprpmi })_{3}(2.66 \mathrm{eV})$. In this series, the $\operatorname{Ir}(\text { iprpmi })_{3}$ concentration range was broadened to cover from $0 \%(\mathrm{~B} 1$, undoped) to $24 \%$ (B6).

The EL spectrum for undoped device B1 is shown in Figure 5(a). The spectrum is invariant with current density and shows a broad peak centered at $484 \mathrm{~nm}$, which can be 
attributed to BAlq [45]. A weak shoulder appears around $400 \mathrm{~nm}$, which can be due to emissions from the host mCBP [46, 47], or the hole-transport layer TAPC [48], or both.
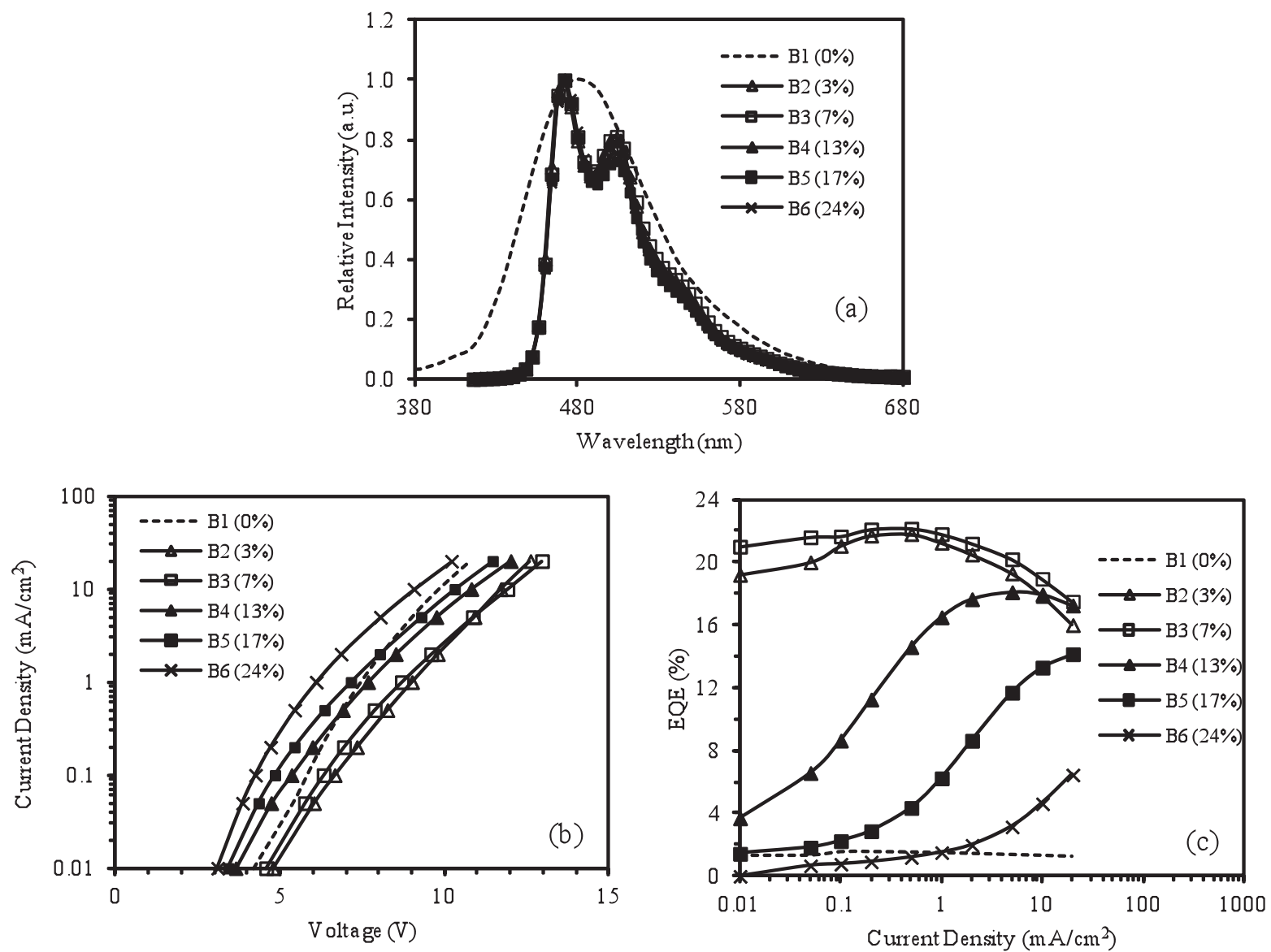

Figure 5: OLED performance data for $\operatorname{Ir}(\text { iprpmi })_{3}$ concentration series with TAPC HTL and BAlq ETL. ITO $/ 1.2 \mathrm{~nm} \mathrm{MoO} / 40 \mathrm{~nm}$ TAPC/30 nm mCBP+ x\% Ir(iprpmi) $)_{3} / 40 \mathrm{~nm}$ BAlq $/ 1 \mathrm{~nm} \mathrm{LiF} / 100 \mathrm{~nm}$ Al. B1 [undoped mCBP], B2 [3\%], B3 [7\%], B4 [13\%], B5 [17\%], B6 [24\%]; (a) EL spectra at $5 \mathrm{~mA} / \mathrm{cm}^{2}$, (b) current density vs. voltage, (c) EQE vs. current density.

Qualitatively, the EL spectrum indicates that electron-hole recombination occurs throughout the emitter layer and at both TAPC and BAlq interfaces adjacent to the emitting layer. The relative intensities of the broad peak and the weak shoulder may indicate that the location of the recombination zone is at or near the BAlq interface. However, this is not necessarily the case as shown in experiments involving doped devices where the recombination zone can be better located. In any case, the EQE of the undoped device is very low compared with the Ir(iprpmi $)_{3}$ doped devices. 
The EL spectra for $\operatorname{Ir}(\text { iprpmi })_{3}$ doped devices are also shown in Figure 5(a). Regardless of the dopant concentration, the EL spectra are similar and characteristic of $\operatorname{Ir}(\text { iprpmi })_{3}$ emission. The corresponding CIEx,y coordinates are 0.17, 0.37.

The J-V plots in Figure 5(b) show that the drive voltage is dependent on the $\operatorname{Ir}(\text { iprpmi })_{3}$ dopant concentration in the emitting layer. At low concentrations as in B2 and B3, the drive voltage (at $5 \mathrm{~mA} / \mathrm{cm}^{2}$ ) is $10.9 \mathrm{~V}$, which is as much as 2 volts higher than undoped device B1 $(9.0 \mathrm{~V})$ at the same current density. With higher concentrations, the drive voltage is reduced. For device B6 with $24 \% \operatorname{Ir}(\text { iprpmi })_{3}$, the drive voltage is about 1 volt less than the undoped cell. These $\mathrm{J}-\mathrm{V}$ characteristics indicate that $\operatorname{Ir}(\text { iprpmi })_{3}$ may act as a charge trap or as a conductive channel. It will be shown that it is the hole-transport in host mCBP that is primarily affected by $\operatorname{Ir}(\text { iprpmi })_{3}$. As shown in Figure 5(c), the EQE is highly sensitive to the $\operatorname{Ir}(\text { iprpmi })_{3}$ concentration in the emitter layer. At low concentrations such as in devices B2 $(3 \%)$ and $\mathrm{B} 3(7 \%)$, the EQE is high and relatively constant, ranging from 18 to $22 \%$ over a wide range of current densities from 0.01 to $20 \mathrm{~mA} / \mathrm{cm}^{2}$ and decreasing only slightly with increasing current density. At high concentrations such as in devices B4 (13\%), B5 (17\%) and B6 (24\%), the EQE is much reduced, but rises rapidly with increasing current density. For B4, the EQE increases from $3.7 \%$ at $0.01 \mathrm{~mA} / \mathrm{cm}^{2}$ to a plateau of nearly $18 \%$ beyond $5 \mathrm{~mA} / \mathrm{cm}^{2}$. For B5 and B6, the EQE is further reduced and the fall-off at low current densities is much worse. The EQE at $0.01 \mathrm{~mA} / \mathrm{cm}^{2}$ is only $1.4 \%$ and $0.4 \%$ for $\mathrm{B} 5$ and $\mathrm{B} 6$, respectively.

The fact that the devices with a lower $\operatorname{Ir}(\text { iprpmi })_{3}$ dopant concentration (B2 and B3) exhibit a higher EQE and require a higher drive voltage indicates that electron-hole recombination and subsequent generation and emission of $\operatorname{Ir}(\text { iprpmi) })_{3}$ excitons occurs mainly near the interface with the hole-transport TAPC layer. Because BAlq is capable of quenching $\operatorname{Ir}(\text { iprpmi })_{3}$ triplet excitons, a lower EQE would have been observed if electron-hole recombination was to occur at the BAlq interface. $\operatorname{Ir}(\text { iprpmi })_{3}$ can affect carrier transport in the emitter layer. Due to its HOMO (4.8 eV) and LUMO (2.2 eV) energies, $\operatorname{Ir}(\text { iprpmi })_{3}$ mainly 
affects the transport of holes in an mCBP matrix, but not electrons. At low $\operatorname{Ir}(\text { iprpmi })_{3}$ concentrations, holes can be effectively trapped by $\operatorname{Ir}(\text { iprpmi })_{3}$, causing recombination to be more localized at the TAPC interface. As a result, the EQE is enhanced as observed in devices B2 and B3, since TAPC, unlike BAlq, is incapable of quenching $\operatorname{Ir}(\text { iprpmi })_{3}$ triplet excitons. As the $\operatorname{Ir}(\text { iprpmi })_{3}$ concentration increases, both the drive voltage and EQE are decreased. The voltage is decreased because $\operatorname{Ir}(\text { iprpmi })_{3}$ molecules at a high concentration can form a continuous phase to accept hole injection from TAPC and to assist the hole transport through the mCBP host matrix. The decrease in EQE can be attributed to two reasons: 1) $\operatorname{Ir}(\text { iprpmi })_{3}$ triplet excitons can diffuse more easily through the $\operatorname{Ir}(\text { iprpmi })_{3}$ phase towards the BAlq interface, where they suffer quenching by BAlq; and 2) increased hole transport through the emitter layer results in increased recombination and exciton quenching at the BAlq interface. As will be shown in section 3.5, self-quenching and/or triplet-triplet annihilation play only a minor role in reducing $\mathrm{EQE}$ in $\operatorname{Ir}(\text { iprpmi) })_{3}$ doped emitters.

The EQE dependence on current density (Figure 5(c)) observed in devices B2-B6 may also be correlated to the hole trapping and transport characteristics of $\operatorname{Ir}(\text { iprpmi })_{3}$. For devices with a low concentration of $\operatorname{Ir}(\text { iprpmi })_{3}$ such as B2 and B3, the total current through the emitter layer is presumably dominated by the electron current as holes are trapped by $\operatorname{Ir}(\text { iprpmi })_{3}$ molecules and the recombination zone is effectively localized at the TAPC interface. High EQE's are maintained in these devices, regardless of the current density, as long as the electron current dominates. With increasing concentration of $\operatorname{Ir}(\text { iprpmi })_{3}$ in the emitter layer such as in devices B3-B6, the charge transport becomes more bi-polar as more holes are transported through $\operatorname{Ir}(\text { iprpmi })_{3}$ in addition to electron transport through mCBP. Since there is no barrier for hole injection from TAPC to $\operatorname{Ir}(\text { iprpmi })_{3}$ in contrast to a large barrier $(0.5 \mathrm{eV})$ for electron injection from BAlq into $\mathrm{mCBP}$, it is likely that the hole current is transport limited whereas the electron current is injection limited, leading to a space distribution of electrons and holes across the emitter layer that is dependent on the bias 
voltage. At a low bias voltage, the hole current dominates as the voltage is not high enough to cause electron injection from BAlq to $\mathrm{mCBP}$, causing the recombination zone to shift towards the BAlq interface, resulting in a decrease in EQE. With increasing bias, more electron injection takes place, causing the recombination zone to shift away from the BAlq interface towards the TAPC interface, resulting in increasing EQE. The extent of this shift in the recombination zone is dependent on the $\operatorname{Ir}(\text { iprpmi })_{3}$ concentration, with the highest concentration resulting in the smallest shift away from the BAlq interface and thus resulting in the lowest EQE.

\subsection{Probing recombination zone:}

In section 3.3 the dopant concentration for each device was fixed throughout the entire mCBP layer. To gain a better understanding of where recombination and emission occurs in the emitter layer, we designed and fabricated devices $\mathrm{C} 1-\mathrm{C} 4$ where the emitter layer is split into two adjoining layers consisting of a layer of $\operatorname{Ir}(\text { iprpmi })_{3}$ doped $\mathrm{mCBP}$ and a layer of undoped mCBP. The general device structure is as follows: ITO/1.2 nm $\mathrm{MoO}_{\mathrm{x}} / 40 \mathrm{~nm}$ TAPC/x nm mCBP+6\% Ir(iprpmi) $3 / \mathrm{y} \mathrm{nm} \mathrm{mCBP/40} \mathrm{nm} \mathrm{BAlq/1} \mathrm{nm} \mathrm{LiF/100} \mathrm{nm} \mathrm{Al,} \mathrm{where} \mathrm{x}$ and $y$ refer to the thicknesses of the adjoined emitting layer. The $\operatorname{Ir}(\text { iprpmi })_{3}$ was kept at $6 \%$, representing the low dopant concentration and optimal EQE derived from devices B2-B6. The total thickness $(\mathrm{x}+\mathrm{y})$ of the doped $(\mathrm{x})$ and undoped (y) layers was kept at $30 \mathrm{~nm}$ with $\mathrm{x}$ and y varied from 5 to $25 \mathrm{~nm}$. Devices C1-C4 exhibit identical EL spectra (not shown), similar to that of device B3 shown in Figure 5(a), indicating that emission is from $\operatorname{Ir}(\text { iprpmi })_{3}$ and the recombination zone is adjacent to the TAPC interface. Figures $6(a)$ and $6(b)$ show the device $\mathrm{J}-\mathrm{V}$ and EQE-J data respectively. Essentially there are only minor differences between the devices $\mathrm{C} 1-\mathrm{C} 4$ and their performance is similar to $\mathrm{B} 3$; there is little difference in drive voltage and the EQE varied from 15 to $20 \%$ among the devices with a mild dependence on current density over a current density range from 0.01 to $20 \mathrm{~mA} / \mathrm{cm}^{2}$. This indicates that the recombination zone is located within the first $5 \mathrm{~nm}$ of the TAPC interface. Furthermore, this 
also provides evidence that triplet $\operatorname{Ir}(\text { iprpmi })_{3}$ excitons are unable to diffuse to the BAlq interface and explains why BAlq can be utilized as the ETL without affecting the device efficiency as long as the $\operatorname{Ir}(\text { iprpmi })_{3}$ dopant concentration in $\mathrm{mCBP}$ is relatively low $(\sim 6 \%)$.
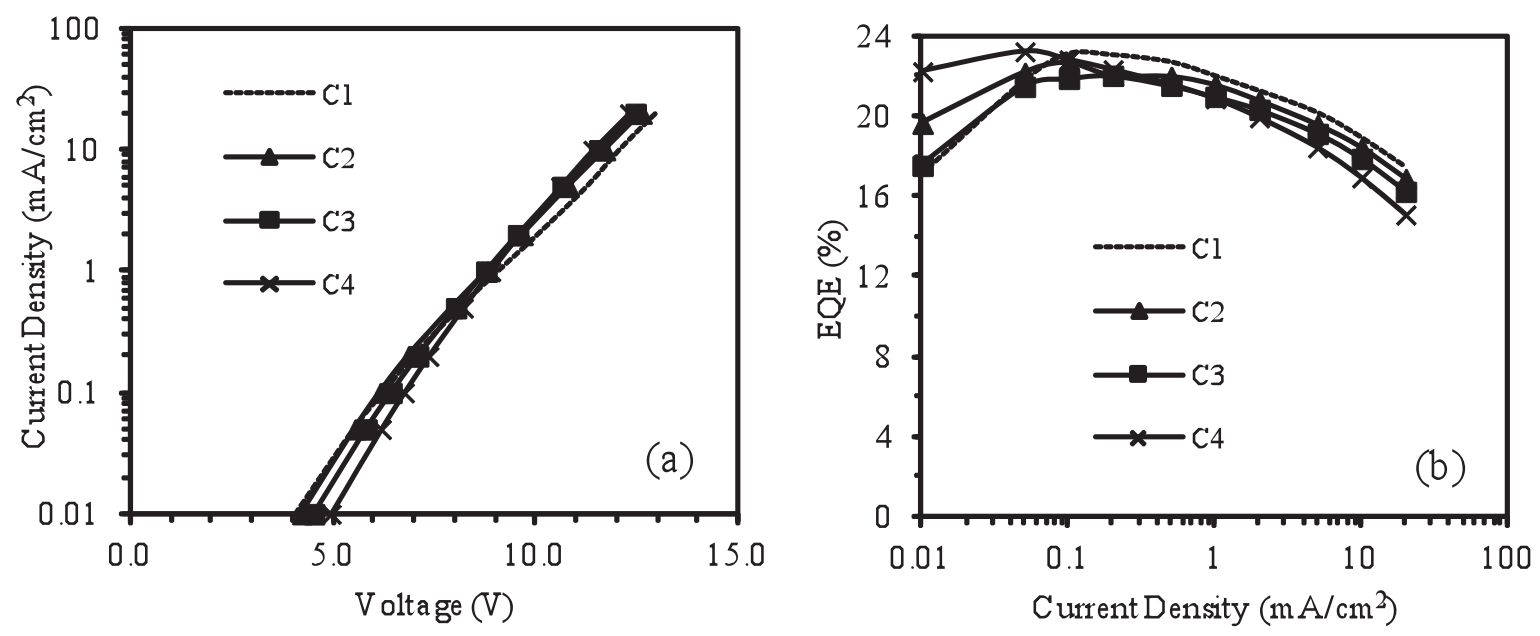

Figure 6: OLED performance data when probing the recombination zone with $6 \% \operatorname{Ir}(\mathrm{iprpmi})_{3}$. ITO/1.2 $\mathrm{nm} \mathrm{MoO}_{\mathrm{x}} / 40 \mathrm{~nm}$ TAPC/x nm mCBP+6\% $\operatorname{Ir}(\text { iprpmi })_{3} / \mathrm{y} \mathrm{nm} \mathrm{mCBP} / 40 \mathrm{~nm} \mathrm{BAlq} / 1 \mathrm{~nm} \mathrm{LiF} / 100 \mathrm{~nm} \mathrm{Al}$. $\mathbf{C 1}[x=25 \mathrm{~nm}, \mathrm{y}=5 \mathrm{~nm}], \mathbf{C 2}[\mathrm{x}=20 \mathrm{~nm}, \mathrm{y}=10 \mathrm{~nm}], \mathbf{C} \mathbf{3}[\mathrm{x}=10 \mathrm{~nm}, \mathrm{y}=20 \mathrm{~nm}]$, and $\mathbf{C 4}[\mathrm{x}=5 \mathrm{~nm}, \mathrm{y}=25 \mathrm{~nm}]$ : (a) current density vs. voltage, (b) EQE vs. current density.

To further illustrate the effect of $\operatorname{Ir}(\text { iprpmi })_{3}$ on the recombination zone shift in the emitter layer, we fabricated devices D1-D4 with a layer structure identical to C1-C4, except that the $\operatorname{Ir}(\text { iprpmi })_{3}$ dopant concentration in the emitter layer was increased to $25 \%$. As in C1-C4, the EL spectra (not shown) for D1-D4 are identical, indicating the emission is from Ir(iprpmi) 3. Also similar to C1-C4, the EQE (Figure 7(b)) for all four devices (D1-D4) is uniformly high (15-18\%) and relatively independent of the current density. This is in direct contrast with the devices having an emitter configuration where the highly doped layer is in direct contact with the BAlq electron-transport layer. As shown in device B6, where a 25\% Ir(iprpmi) doped layer is in contact with BAlq, the EQE is low $(<7 \%)$ and highly dependent on current density. Evidently, it is critical to separate the doped mCBP layer from the BAlq interface at high $\operatorname{Ir}(\text { iprpmi })_{3}$ concentrations in order to avoid exciton quenching by the BAlq and achieve high EQE values. However, the presence of an undoped mCBP layer can 

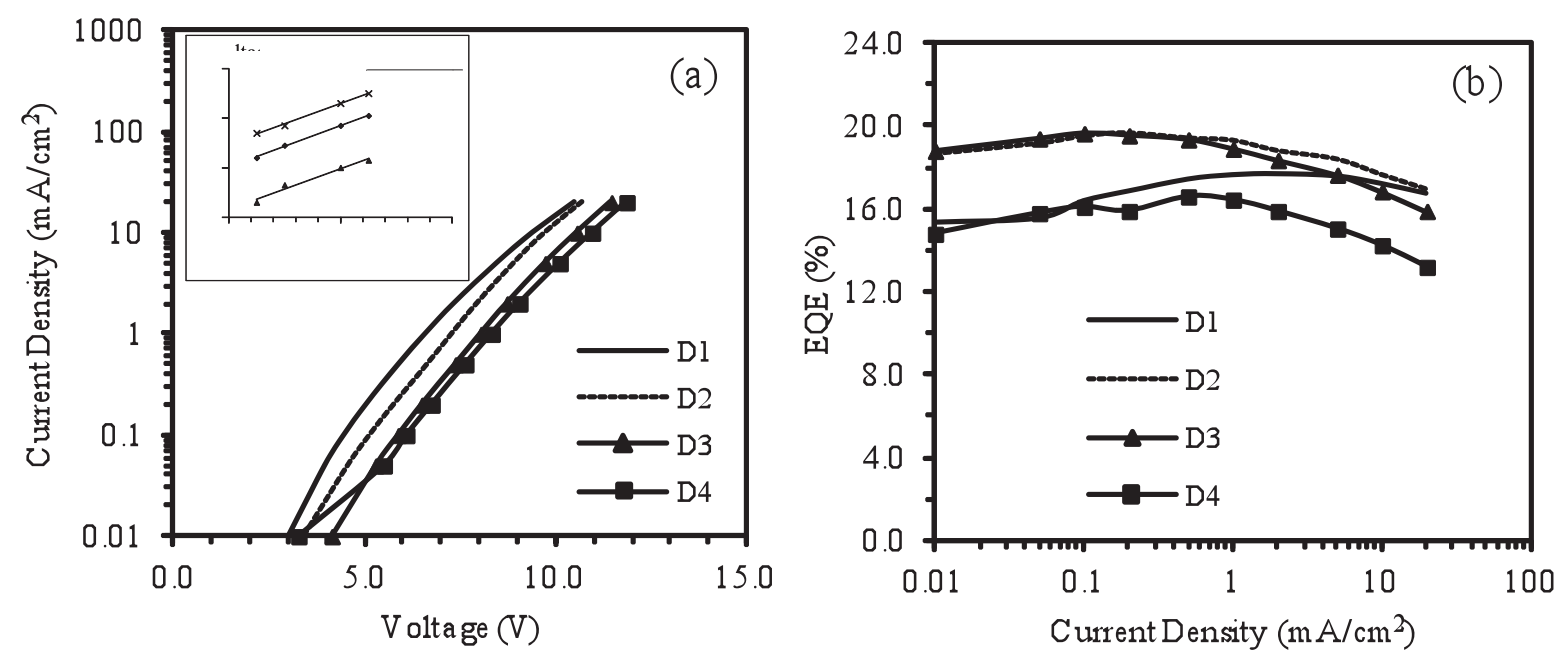

Figure 7: OLED performance data when probing the recombination zone with $25 \% \operatorname{Ir}(\text { iprpmi })_{3}$. ITO/1.2 $\mathrm{nm} \mathrm{MoO}_{\mathrm{x}} / 40 \mathrm{~nm}$ TAPC/x nm mCBP+25\% Ir(iprpmi) $)_{3} / \mathrm{y} \mathrm{nm} \mathrm{mCBP} / 40 \mathrm{~nm} \mathrm{BAlq} / 1 \mathrm{~nm} \mathrm{LiF} / 100 \mathrm{~nm} \mathrm{Al}$. D1 $[x=25 \mathrm{~nm}, y=5 \mathrm{~nm}], \mathbf{D} 2[x=20 \mathrm{~nm}, y=10 \mathrm{~nm}], \mathbf{D} 3[x=10 \mathrm{~nm}, \mathrm{y}=20 \mathrm{~nm}]$, and $\mathbf{D} 4[x=5 \mathrm{~nm}, \mathrm{y}=25 \mathrm{~nm}]$ : (a) current density vs. voltage [ inset: voltage vs mCBP layer thickness of devices D1-D4 under current densities of 1,5 , and $10 \mathrm{~mA} / \mathrm{cm}^{2}$ ] (b) EQE vs. current density.

significantly increase the drive voltage depending on the layer thickness. As shown in Figure 7(a) for devices D1-D4, the increase in voltage can be as large as 2 volts with a $25 \mathrm{~nm}$ undoped mCBP layer, which apparently blocks hole injection from the mCBP doped layer. The inset of Figure 7(a) shows a linear relationship between device voltage and the undoped mCBP layer thickness, indicating the electric field across undoped $\mathrm{mCBP}$ is constant.

Devices D1-D4 all have high EQE's because the undoped mCBP layer prevents recombination from occurring at the EML/BAlq interface while also preventing triplet excitons from diffusing to this interface. There are noteworthy trends among the EQE-J curves displayed in Figure 7(b). Depending on current density, the EQE ranges from 15-18\% for D1, 16-20\% for D2 and D3, and 13-17\% for D4. D2 and D3 have the highest EQE's. Apparently an undoped mCBP layer of $10-20 \mathrm{~nm}$ thick is needed to completely eliminate the influence of BAlq. With only $5 \mathrm{~nm}$ undoped mCBP, D1 has a lower efficiency presumably from BAlq quenching. D4 has a $25 \mathrm{~nm}$ thick layer of undoped mCBP which is sufficient to prevent BAlq quenching and yet the EQE is somewhat lower than D2 and D3. A possible explanation is that D4 has a thin doped layer which, being only $5 \mathrm{~nm}$ thick, can lead to a 
higher density of triplet excitons and consequently a higher rate of triplet-triplet annihilation and/or exciton-polaron interactions.

\subsection{High EQE, low voltage OLEDs:}

Of all the devices described so far, B2 and B3 have the highest EQE's but also a relatively high drive voltage due to primarily the use of BAlq as the electron-transport layer, which has a low electron mobility of $10^{-5} \mathrm{~cm}^{2} / \mathrm{Vs}$ [49]. By replacing BAlq with TmPyPB, a known electron-transport material of high mobility $\left(10^{-3} \mathrm{~cm}^{2} / \mathrm{Vs}\right)[36]$, we were able to demonstrate both high EQE and low voltage in devices E1-E5 with the following structure: ITO/1.2 nm MoO $/ 40 \mathrm{~nm}$ TAPC/30 nm mCBP+x\% Ir(iprpmi) $)_{3} / 40 \mathrm{~nm}$ TmPyPB/1 nm LiF/100 $\mathrm{nm} \mathrm{Al}$. The Ir(iprpmi $)_{3}$ concentration ranged from $3 \%$ in E1 to $24 \%$ in E5.

The J-V characteristics for E1-E5 are shown in Figure 8(a) and indicate a clear reduction in drive voltage with TmPyPB as the ETL. Furthermore, similar to what was observed for devices B2-B6, the drive voltage decreases as the dopant concentration increases. A reduction of approximately $1 \mathrm{~V}$ is realized from E1 (3\% dopant) to E5 (24\% dopant). As shown in Figure 8(b), high EQE's were obtained in all E1-E5 devices, ranging
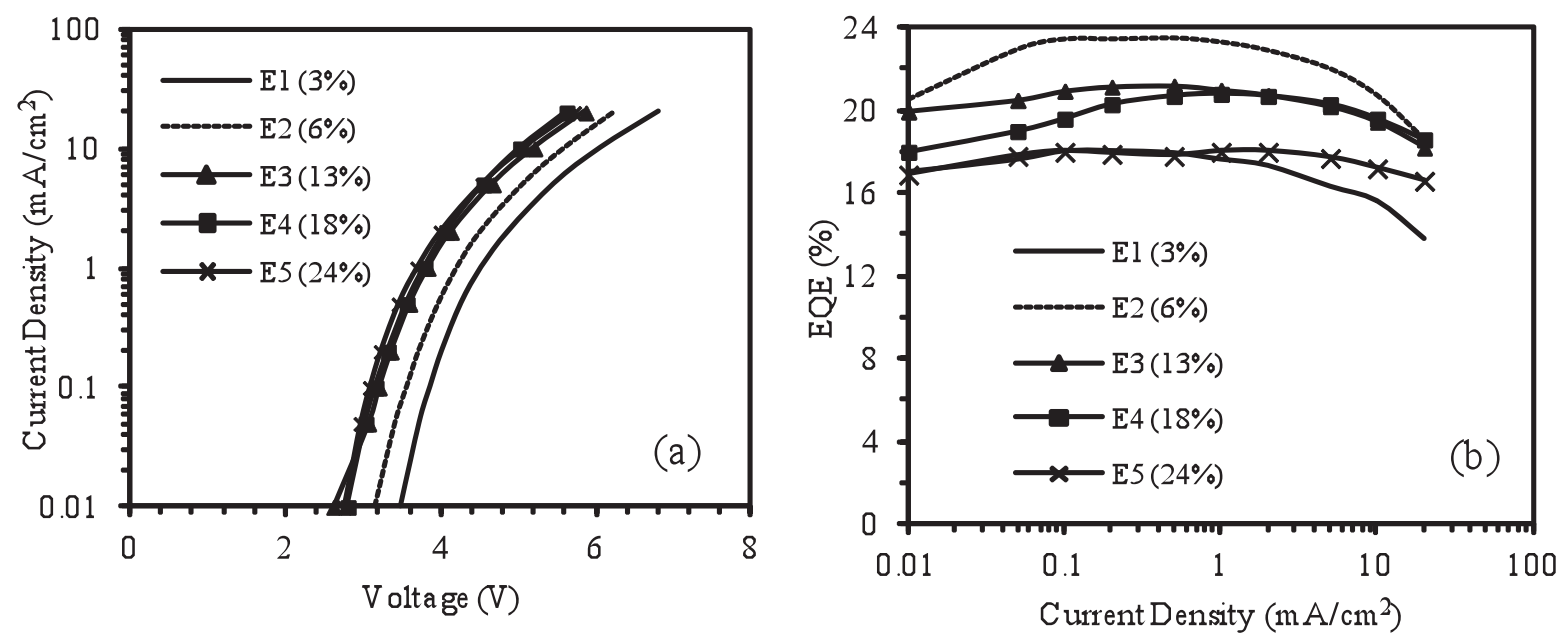

Figure 8: OLED performance data for Ir(iprpmi) $)_{3}$ concentration series with TmPyPB ETL. ITO/1.2 nm MoO $/ 40 \mathrm{~nm}$ $\mathrm{TAPC} / 30 \mathrm{~nm} \mathrm{mCBP}+\mathrm{x} \% \mathrm{Ir}(\mathrm{iprpmi})_{3} / 40 \mathrm{~nm} \mathrm{TmPyPB} / 1 \mathrm{~nm} \mathrm{LiF} / 100 \mathrm{~nm} \mathrm{Al} \mathbf{E}$ [33\%], E2[6\%], E3[13\%], E4[18\%], and E5[24\%]. (a) current density vs. voltage, (b) EQE vs. current density. 
from $15 \%-23 \%$, depending on dopant concentration and current density. The efficiency remains high regardless of dopant concentration because TmPyPB has a triplet energy of 2.78 $\mathrm{eV}$ and is unable to quench the $\operatorname{Ir}(\text { iprpmi })_{3}$ triplet excitons. This also indicates that selfquenching and/or triplet-triplet annihilation plays only a minor role in reducing the EQE.

\subsection{Device Lifetime:}

Lifetime testing was conducted on several representative $\operatorname{Ir}(\text { iprpmi })_{3}$ doped devices containing various hole and electron transport layers. For A1 and A2, NPB was used as the hole-transport layer, and BAlq as the electron-tranport layer; with $\operatorname{Ir}(\text { iprpmi })_{3}$ concentrations of $6 \%$ and $12 \%$, respectively. For B3 and B4, TAPC was used as the hole-transport layer, otherwise the layer formulations are essentially the same as A1 and A2. For E5, TAPC and TmPyPB were the hole-transport layer and electron-transport layer, respectively. It can be seen from Figure 9 that the half-life (at a constant current of $5 \mathrm{~mA} / \mathrm{cm}^{2}$ ), while quite short for all devices - less than 100 hours, is rather dependent on the transport layers. Among the devices, E2, with TAPC and TmPyPB as the hole and electron transport layers, respectively,

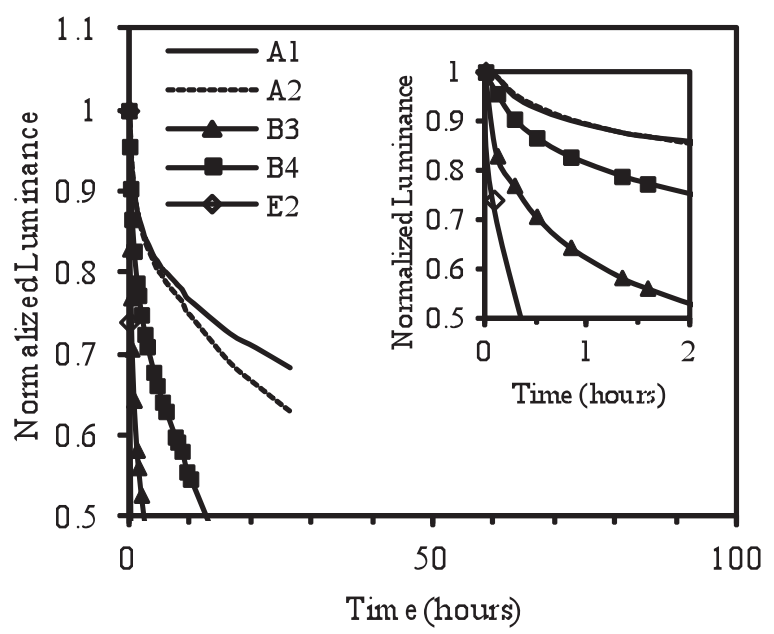

Figure 9: Lifetime testing at $5 \mathrm{~mA} / \mathrm{cm}^{2}$ for device structure, ITO/1.2 $\mathrm{nm} \mathrm{MoO} / 40 \mathrm{~nm} \mathrm{HTL} / 30 \mathrm{~nm}$ $\mathrm{mCBP}+\mathbf{x} \%$ Ir(iprpmi) 3 /40 nm ETL, A1 [NPB-6\%-BAlq], A2 [NPB-12\%-BAlq], B3 [TAPC-7\%-BAlq], B4 [TAPC-13\%-BAlq], E2 [TAPC-6\%-TmPyPB].

is the most short-lived with a half-life of less than $1 / 2$ hour (see Figure 9 insert), whereas A1 and $\mathrm{A} 2$, with $\mathrm{NPB}$ and $\mathrm{BAlq}$ replacing $\mathrm{TAPC}$ and TmPyPB, respectively, are the most stable 
with a half-life in the range of 50-80 hours. With TAPC as the hole-transport layer and BAlq as the electron-transport layer, B2 and B3 have an intermediate half-life in the range of 2-10 hours, respectively. The variation in lifetimes with the transport layers indicates that the instability in these phosphorescent blue devices may not necessarily be due to the emitter layer. It is known that fluorescent OLED devices are more stable with NPB instead of TAPC as the hole-transport layer $[50,51]$. As an electron-transport material, BAlq is known to improve device stability [50]. The better stability of A1 and A2 are in large part due to the use of NPB and BAlq as the respective hole and electron transport layers, suggesting that recombination in these layers or at their interfaces with the emitter layer, be it a fluorescent or phosphorescent emitter, are most detrimental to the operational stability. Comparing A1 and A2, A1 has a longer half-life (80 vs. 50 hours) but a lower EQE (7\% vs. 13\%). This correlation of higher stability with lower efficiency also applies to devices B2 and B3, implying that the formation of triplet excitons invariably also leads to device degradation.

The observed lifetimes for A1 and A2 are inferior to what was reported by Lin et al. [26] where lifetimes reached $\sim 400-700 \mathrm{hrs}$. using $\operatorname{Ir}(\mathrm{iprpmi})_{3}$ as the emitter. These disparities in lifetime can be attributed to different device architectures and initial EQE's.

The lifetime data presented here show that $\operatorname{Ir}(\text { iprpmi })_{3}$-based devices with suitable transport layers have longer lifetimes compared to FIrpic-based devices. In Flrpic-based devices, the observed short lifetime, which is independent of the transport layer, has been attributed to the electrochemical degradation of Flrpic molecules related to its fluorine substituents and the picolinate ligand. These structural features are not present in $\operatorname{Ir}(\text { iprpmi })_{3}$. Since recombination and emission can be engineered to take place largely at the holetransport interface using low-concentrations of phosphorescent dopants as hole traps, the ETL material has no significant impact on device lifetime. Thus device stability is more hinged on the selection of hole-transport materials as well as the host materials for the emitter, assuming that the Ir-based dopant is relatively stable. We have shown in this study how important a role 
the HTL material plays for both device EQE and lifetime. Since amines and carbazoles are known to undergo homolytic $\mathrm{C}-\mathrm{N}$ bond cleavage in the excited state [51-53], it is likely that these common classes of hole-transport materials are prompt to degrade in blue phosphorescent emitters because of possible recombination in the hole-transport layer or interface resulting in excitons with energy exceeding the dissociation energy of the C-N bonds. It follows that none of the HTL materials used in this study are practical for achieving lifetimes that match those of green and red phosphorescent devices, where the low-energy dopants can suppress recombination in both hole and electron transport layers. To significantly improve the stability of blue phosphorescent devices, new hole-transport materials will be needed.

\section{Conclusion:}

We have investigated $\operatorname{Ir}(\text { iprpmi })_{3}$ as a dopant in blue phosphorescent emitters with $\mathrm{mCBP}$ as the host and various materials as the hole and electron transport layers. We have shown that $\operatorname{Ir}(\text { iprpmi) })_{3}$ as a dopant in the host mCBP is capable of trapping (at low concentration) and transporting (at high concentration) holes. Utilizing $\operatorname{Ir(iprpmi})_{3}$ to trap holes, the recombination zone can be confined at or near the hole-transport layer. As a result, EQE values obtained are highly dependent on the HTL used. With TAPC as HTL, which does not quench $\operatorname{Ir}(\text { iprpmi })_{3}$ triplet excitons, EQE's over $20 \%$ have been achieved. Utilizing $\operatorname{Ir}(\text { iprpmi })_{3}$ for hole transport, the recombination zone can be shifted towards the ETL. With low-triplet BAlq as the ETL, much reduced EQE's are obtained that vary not only with dopant concentration but also electric field, indicating various extent of exciton quenching by BAlq. Quenching by the ETL can be eliminated and high EQE's retained by inserting a thin undoped mCBP layer between the ETL and EML. We show that device lifetime using $\operatorname{Ir}(\text { iprpmi })_{3}$ as the emitting dopant is significantly improved compared to when FIrpic is the emitting dopant. Furthermore, device lifetime is highly dependent on the choice of host and hole/electron transport layers. 


\section{Acknowledgements:}

This material is based upon work supported by the Department of Energy (DOE) under Award No. DE-EE0003296. K. P. Klubek acknowledges support from the National Science Foundation (NSF) under Grant No. 1316969 and the NSF Graduate Research Fellowship Program under Grant No. 0935947. S. C. Dong acknowledges support from the National Postdoctoral Science Foundation of China under Grant No. 2012M511797. Any opinions, findings, and conclusions or recommendations expressed in this material are those of the authors and do not necessarily reflect the views of the NSF or DOE. 


\section{References:}

[1] C. Adachi, M.A. Baldo, S.R. Forrest, S. Lamansky, M.E. Thompson, R.C. Kwong, Appl. Phys. Lett., 78 (2001) 1622 .

[2] M.A. Baldo, S. Lamansky, P.E. Burrows, M.E. Thompson, S.R. Forrest, Appl. Phys. Lett., 75 (1999) 4.

[3] S. Lamansky, P.I. Djurovich, D. Murphy, F. Abdel-Razzaq, H.-E. Lee, C. Adachi, P.E. Burrows, S.R. Forrest, M.E. Thompson, J. Am. Chem. Soc., 123 (2001) 4304.

[4] T. Tsutsui, M.-J. Yang, M. Yahiro, K. Nakamura, T. Watanabe, T. Tsuji, Y. Fukuda, T. Wakimoto, S. Miyaguchi, Jpn. J. Appl. Phys., 38 (1999) L1502.

[5] C. Adachi, M.A. Baldo, M.E. Thompson, S.R. Forrest, J. Appl. Phys., 90 (2001) 5048.

[6] H. Yersin, A.F. Rausch, R. Czerwieniec, T. Hofbeck, T. Fischer, Coord. Chem. Rev., 255 (2011) 2622.

[7] M. Segal, C. Mulder, K. Celebi, M. Singh, K. Rivoire, S. Difley, T. Van Voorhis, M.A. Baldo, Proc. SPIE, 6999 (2008) 699912.

[8] K.S. Yook, J.Y. Lee, Adv. Mater., 24 (2012) 3169

[9] N. Chopra, J. Lee, Y. Zheng, S.-H. Eom, J. Xue, F. So, Appl. Phys. Lett., 93 (2008) 143307.

[10] H. Sasabe, E. Gonmori, T. Chiba, Y.-J. Li, D. Tanaka, S.-J. Su, T. Takeda, Y.-J. Pu, K.-i. Nakayama, J. Kido, Chem. Mater., 20 (2008) 5951.

[11] S.-J. Su, E. Gonmori, H. Sasabe, J. Kido, Adv. Mater., 20 (2008) 4189.

[12] J. Lee, J.-I. Lee, J.Y. Lee, H.Y. Chu, Appl. Phys. Lett., 94 (2009) 193305.

[13] L. Xiao, S.-J. Su, Y. Agata, H. Lan, J. Kido, Adv. Mater., 21 (2009) 1271.

[14] C.W. Lee, J.Y. Lee, Adv Mater, 25 (2013) 5450.

[15] W. Sotoyama, T. Satoh, M. Kinoshita, M. Tobise, K. Kawato, T. Ise, H. Takizawa, S. Yamashita, Dig. Tech. Pap. Soc. Inf. Disp. Int. Symp., 41 (2010) 556.

[16] H. Lee, H. Ahn, C. Lee, J. Inf. Disp., 12 (2011) 219.

[17] I. Rabelo de Moraes, S. Scholz, B. Luessem, K. Leo, Org. Electron., 12 (2011) 341.

[18] K.S. Yook, O.Y. Kim, J.Y. Lee, Synth. Met., 161 (2011) 2677.

[19] V. Sivasubramaniam, F. Brodkorb, S. Hanning, H.P. Loebl, V. van Elsbergen, H. Boerner, U. Scherf, M. Kreyenschmidt, J. Fluorine Chem., 130 (2009) 640.

[20] E. Baranoff, B.F.E. Curchod, J. Frey, R. Scopelliti, F. Kessler, I. Tavernelli, U. Rothlisberger, M. Gratzel, M.K. Nazeeruddin, Inorg. Chem., 51 (2012) 215.

[21] K.P. Klubek, C.W. Tang, L.J. Rothberg, Org. Electron., 15 (2014) 1312.

[22] N.C. Giebink, B.W. D'Andrade, M.S. Weaver, P.B. Mackenzie, J.J. Brown, M.E. Thompson, S.R. Forrest, J. Appl. Phys., 103 (2008) 044509.

[23] H. Yamamoto, J. Brooks, M.S. Weaver, J.J. Brown, T. Murakami, H. Murata, Appl. Phys. Lett., 99 (2011) 033301.

[24] K. Udagawa, H. Sasabe, C. Cai, J. Kido, Adv. Mater. (Weinheim, Ger.), 26 (2014) 5062.

[25] J. Zhuang, W. Li, W. Su, Y. Liu, Q. Shen, L. Liao, M. Zhou, Org. Electron., 14 (2013) 2596.

[26] C. Lin, P.B. MacKenzie, R.W. Walters, J.-Y. Tsai, C.S. Brown, J. Deng, U.S. Patent No. 7,902,374 (March 8, 2011).

[27] D.B. Knowles, C. Lin, P.B. Mackenzie, J.-Y. Tsai, R.W. Walters, S.A. Beers, C.S. Brown, W.H. Yeager, U.S. Patent No. 7,915,415 (March 29, 2011).

[28] V. Adamovich, M.S. Weaver, B. D'Andrade, U.S. Patent No. 8,580,402 (November 12, 2013).

[29] B. D'Andrade, P.B. MacKenzie, M.S. Weaver, J.J. Brown, U.S. Patent No. 8,557,399 (October 15, 2013).

[30] M.E. Kondakova, T.D. Pawlik, R.H. Young, D.J. Giesen, D.Y. Kondakov, C.T. Brown, J.C. Deaton, J.R. Lenhard, K.P. Klubek, J. Appl. Phys., 104 (2008) 094501.

[31] N.C. Giebink, B.W. D'Andrade, M.S. Weaver, J.J. Brown, S.R. Forrest, J. Appl. Phys., 105 (2009) 124514.

[32] C.W. Lee, J.Y. Lee, Org. Electron., 14 (2013) 370.

[33] M.E. Kondakova, J.C. Deaton, T.D. Pawlik, D.J. Giesen, D.Y. Kondakov, R.H. Young, T.L. Royster, D.L. Comfort, J.D. Shore, J. Appl. Phys., 107 (2010) 014515.

[34] H. Nakanotani, K. Masui, J. Nishide, T. Shibata, C. Adachi, Sci Rep, 3 (2013) 2127.

[35] D.P.-K. Tsang, M.-Y. Chan, A.Y.-Y. Tam, V.W.-W. Yam, Org. Electron., 12 (2011) 1114.

[36] S.-J. Su, T. Chiba, T. Takeda, J. Kido, Adv. Mater., 20 (2008) 2125.

[37] M.J.T. Frisch, G. W.; Schlegel, H. B.; Scuseria, G. E.; Robb, M. A.; Cheeseman, J. R.; Montgomery, Jr., J. A.; Vreven, T.; Kudin, K. N.; Burant, J. C.; Millam, J. M.; Iyengar, S. S.; Tomasi, J.; Barone, V.; Mennucci, B.; Cossi, M.; Scalmani, G.; Rega, N.; Petersson, G. A.; Nakatsuji, H.; Hada, M.; Ehara, M.; Toyota, K.; Fukuda, R.; Hasegawa, J.; Ishida, M.; Nakajima, T.; Honda, Y.; Kitao, O.; Nakai, H.; Klene, M.; Li, X.; Knox, J. E.; Hratchian, H. P.; Cross, J. B.; Bakken, V.; Adamo, C.; Jaramillo, J.; Gomperts, R.; Stratmann, R. E.; Yazyev, O.; Austin, A. J.; Cammi, R.; Pomelli, C.; Ochterski, J. W.; Ayala, P. Y.; Morokuma, K.; Voth, G. A.; Salvador, P.; Dannenberg, J. J.; Zakrzewski, V. G.; Dapprich, S.; Daniels, A. D.; Strain, M. C.; Farkas, O.; Malick, D. K.; Rabuck, A. D.; Raghavachari, K.; Foresman, J. B.; Ortiz, J. V.; Cui, Q.; Baboul, A. G.; Clifford, S.; Cioslowski, J.; Stefanov, B. B.; Liu, G.; Liashenko, A.; Piskorz, P.; Komaromi, I.; Martin, R. L.; Fox, D. J.; Keith, T.; Al-Laham, M. A.; Peng, C. Y.; Nanayakkara, A.; Challacombe, M.; Gill, P. M. W.; Johnson, B.; Chen, W.; Wong, M. W.; Gonzalez, C.; and Pople, J. A., Gaussian 03, Revision C.02, Gaussian, Inc., Wallingford CT, 2004.

[38] A.B. Tamayo, B.D. Alleyne, P.I. Djurovich, S. Lamansky, I. Tsyba, N.N. Ho, R. Bau, M.E. Thompson, J. Am. Chem. Soc., 125 (2003) 7377.

[39] T. Fei, X. Gu, M. Zhang, C. Wang, M. Hanif, H. Zhang, Y. Ma, Synth. Met., 159 (2009) 113. 
[40] S.J. Lee, K.-M. Park, K. Yang, Y. Kang, Inorg. Chem., 48 (2009) 1030.

[41] T. Karatsu, M. Takahashi, S. Yagai, A. Kitamura, Inorg. Chem., 52 (2013) 12338.

[42] J.J. Brooks, R.C. Kwong, Y.-J. Tung, M.S. Weaver, B.W. D'Andrade, V. Adamovich, M.E. Thompson, S.R. Forrest, J.J. Brown, Proc. SPIE, 5519 (2004) 35.

[43] S.-J. Yeh, M.-F. Wu, C.-T. Chen, Y.-H. Song, Y. Chi, M.-H. Ho, S.-F. Hsu, C.H. Chen, Adv. Mater., 17 (2005) 285.

[44] F.-C. Fang, Y.-L. Liao, K.-T. Wong, M.-H. Tsai, H.-W. Lin, H.-C. Su, C.-c. Wu, C.-I. Wu, Proc. SPIE-Int. Soc. Opt. Eng., 6192 (2006) 61921R.

[45] J.-h. Niu, W.-1. Li, H.-z. Wei, M.-t. Li, W.-m. Su, Q. Xin, Z.-q. Zhang, Z.-z. Hu, J. Phys. D Appl. Phys., 38 (2005) 1136.

[46] P. Schroegel, N. Langer, C. Schildknecht, G. Wagenblast, C. Lennartz, P. Strohriegl, Org. Electron., 12 (2011) 2047.

[47] S. Gong, X. He, Y. Chen, Z. Jiang, C. Zhong, D. Ma, J. Qin, C. Yang, J. Mater. Chem., 22 (2012) 2894.

[48] K.B. Kahen, J.R. Vargas, D.Y. Kondakov, C.T. Brown, L. Cosimbescu, V. Jarikov, US Pub. No. 2003/0161368, (August 28, 2003).

[49] J.H. Seo, K.H. Lee, B.M. Seo, J.R. Koo, S.J. Moon, J.K. Park, S.S. Yoon, Y.K. Kim, Org. Electron., 11 (2010) 1605.

[50] T. Watanabe, K. Nakamura, S. Kawami, Y. Fukuda, T. Tsuji, T. Wakimoto, S. Miyaguchi, Proc. SPIE-Int. Soc. Opt. Eng., 4105 (2001) 175.

[51] D.Y. Kondakov, W.C. Lenhart, W.F. Nichols, J. Appl. Phys., 101 (2007) 024512.

[52] D.Y. Kondakov, J. Appl. Phys., 104 (2008) 084520.

[53] D.Y. Kondakov, Proc. SPIE, 7051 (2008) 70510I. 

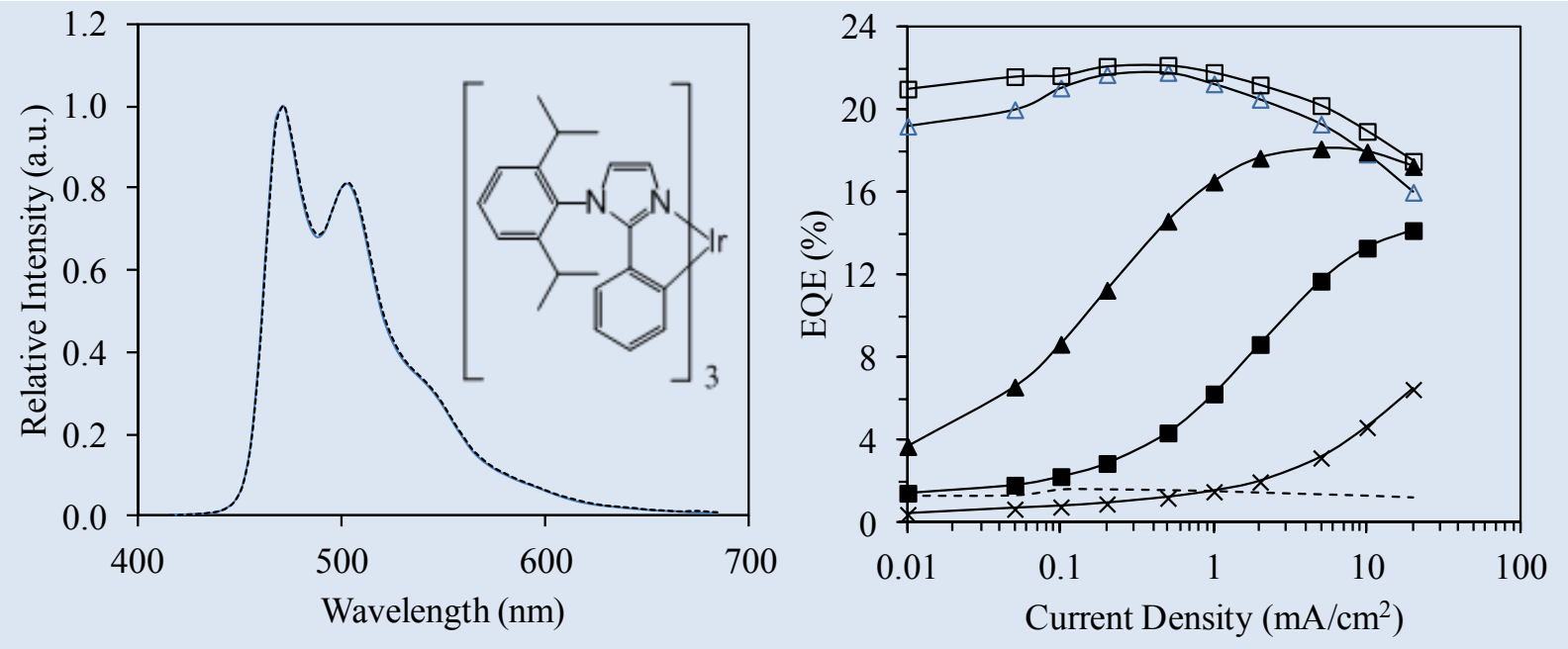